\title{
Marketing actions that influence estimates of others also shape identity
}

\author{
Katherine A. Burson ${ }^{a, *}$, Andrew D. Gershoff ${ }^{b}$ \\ ${ }^{a}$ Ross School of Business, University of Michigan, 701 Tappan Street, Ann Arbor, MI 48109, United States \\ ${ }^{\mathrm{b}}$ McCombs School of Business, University of Texas at Austin, 1 University Station, Austin, TX 78712, United States
}

Received 28 December 2013; received in revised form 19 December 2014; accepted 9 January 2015

Available online 16 January 2015

\begin{abstract}
Consumers' social identities stem from comparisons between themselves and others. These identities help determine consumption decisions. Unfortunately, perceptions of comparative traits and characteristics are frequently biased, which can lead to similarly biased consumption decisions. Five studies show that two incidental but commonplace marketing decisions can influence consumers' estimates of their relative standing and thus their social identities by influencing estimates of how other consumers are distributed.

(C) 2015 Society for Consumer Psychology. Published by Elsevier Inc. All rights reserved.
\end{abstract}

Keywords: Availability; Identity; Distribution estimates; Social identity; Relative standing

Identities are mental representations of how people view themselves through their traits, goals, and characteristics (Oyserman, 2009). Individuals maintain multiple identities, both personal (focusing on characteristics of the individual) and social. Social identities are linked to a social role or group that a person was, is, or may become a member of (e.g., golfer, conservative, environmentalist, trivia expert, or tall person) and therefore differ from personal identities in that they require social comparison.

Ample research shows how consumers' identities influence their attitudes and choices. For example, global versus local identities can influence preferences for products targeted to global versus local markets (Zhang \& Khare, 2009). Moral and gender identities can influence charitable donations associated with inversus out-groups (Winterich, Mittal, \& Ross, 2009). Social identities can influence food choices and alcohol consumption (Berger \& Rand, 2008). The desire to validate and communicate identities has even been linked to brand choices (Aaker, 1997; Chernev, Hamilton, \& Gal, 2011). In addition, identities have been shown to influence self-regulation and impulsiveness in purchase behavior and consumption, especially when one's identity is

\footnotetext{
* Corresponding author.

E-mail addresses: kburson@umich.edu (K.A. Burson), andrew.gershoff@mccombs.utexas.edu (A.D. Gershoff).
}

perceived as less valued compared to others (Johnson, Richeson, \& Finkel, 2011; Verplanken \& Sato, 2011).

An important element in the construction and understanding of social identities is comparison with others (Berger \& Rand, 2008; Festinger, 1954; Miller, Turnbull, \& McFarland, 1988). Identities about intelligence, commitment to a cause, athleticism, and even body size are inherently relative (e.g. Biernat, 2003; Oyserman, 2001; Raeff, 1997). That is, people assess their own position compared to others - their relative standing - in the process of assessing their identity in these types of domains.

Identity-relevant perceptions of relative standing are important because they can affect choices such as clothing size, serving size, and sophistication level of athletic or technology products. For example, consumers prefer higher end and more advanced products if they identify themselves as above average in a given domain (e.g. Burson, 2007). Given this role of perceived relative standing in consumption decisions, it is important that researchers explore factors that may influence them as they may lead to biased consumption.

The current research explores how subtle contextual cues in shopping environments may shift consumers' estimates of relative standing, not by altering estimates of consumers' own abilities, behaviors, or traits, but instead by influencing estimates of how others in the population are distributed across 
characteristics or traits relevant to social identity. We explore two simple manipulations that are common to the marketplace: categorization schemas provided for self-identification, and targeting of consumers in distributional extremes. Five studies (examining intelligence, athletic ability, environmental concern, political conservatism, and physical characteristics) show that a) these manipulations influence estimates of how others are distributed, b) these estimates influence relative perceptions of one's self, and c) they lead to identity-congruent behaviors, all without necessarily shifting consumers perceptions of their own absolute abilities, behaviors, or traits.

\section{Theoretical background}

People regularly make comparative judgments of their own traits, attitudes, behaviors, and characteristics (e.g., Festinger, 1954; Kruglanski \& Mayseless, 1990). For consumers, these judgments are important for product search (Moorman, Diehl, Brinberg, \& Kidwell, 2004), choice (Burson, 2007; Gershoff \& Burson, 2011; Prelec, Wernerfelt, \& Zettelmeyer, 1997), and intentions to seek medical treatment (Menon, Block, \& Ramanathan, 2002). Unfortunately, these judgments are prone to systematic biases. Even after correctly estimating their absolute standing (e.g. own knowledge in a domain), judges overestimate the dispersion of other consumers (others' knowledge), so they imagine more people below them when their absolute standing happens to be high, and more above them when absolute standing happens to be low (Gershoff \& Burson, 2011).

Nisbett and Kunda (1985) argued that overly-disperse distributions are imagined because instances at the extremes are more cognitively available than those in the middle. Manipulating availability has been shown to exacerbate this: Participants seeing pictures of tall (short) consumers believed they were relatively shorter (taller) than others because they imagined more people in the available tail of the distribution (Gershoff \& Burson, 2011).

Though the impact of explicitly increasing the availability of extreme others is relevant to marketing contexts, results such as this could easily be attributed to heavy-handed manipulations: Participants must estimate a distribution for which they are provided only extreme members, so of course they incorporate that relevant data. Thus, in the present experiments, we examine the role of more subtle yet normatively irrelevant cues that may influence distributional estimates.

A large body of research has shown that relative estimates about a wide array of topics can be systematically manipulated (see Moore, 2007 for a review). In some cases, manipulations that cause participants to shift the imagined distribution of others on some target trait or characteristic and thus their placement in that distribution are also essentially shifting their social identity. Social identities are contextualized, highly sensitive to situational cues, and can be subtly cued without the consumer's awareness (Oyserman, 2009; Oyserman, Elmore, \& Smith, 2012). One such contextual cue is how we compare to others (Oyserman, 2001).

We identify two marketing conventions that can subtly influence consumers' identities by shaping comparisons with others-marketer provided category schemas and the marketer's product mix decisions. First, marketers often provide a category schema and ask consumers to identify which category they belong to. For example, a clothing store might ask consumers to identify themselves as petite, small, medium, large, misses, x-large, etc. When presented with such schemas, consumers tend to believe that there is reason and purpose in the asking: Categories meaningfully discriminate among consumers (Grice, 1975). Indeed, it would not be useful to offer a schema in which all consumers fell into the same category. So, when consumers are given category options, they rationally assume that those options are meaningful - that the endpoints of the set of categories will contain people in the extremes of the distribution and points in the middle will contain those who are more typical (e.g., Schwarz, 1994, 1996, 1999; Schwarz, Hippler, Deutsch, \& Strack, 1985; Schwarz \& Scheuring, 1988).

Prior research exploring how people report their own behavior supports this notion. For example, respondents reported watching more television when possible responses included more categories of frequent watching, compared to when there were more possible responses of infrequent watching (Schwarz et al., 1985). And, there is some evidence that estimates of the "average citizen's" behavior are also shifted by category manipulations (see also Schwarz \& Scheuring, 1988). Social identity hinges on assumptions about others, and some information about others comes from the categorization schema. In fact, the more one thinks about others, the more one is susceptible to schema manipulations (Haberstroh, Oyserman, Schwarz, Kühnen, \& Ji, 2002).

While this past work assumes that changes in relative estimates also occur, we strive to document those categorydriven shifts. We propose that the category schemas that group consumers influence the way in which consumers see the full distribution of others, even in domains in which perceptions of their own absolute behaviors, attitudes, or abilities, remain fixed. This change in the perception of others alone biases how consumers see themselves relative to others. If consumers are likely to overly distribute others across all possible categories, then providing more categories at one end or the other of the range of performances should influence their estimates of others. This will lead to biased perceptions of relative standing higher estimates of relative standing when there are many low categories and lower estimates of relative standing when there are many high categories - and this, in turn, will influence perceptions of social identity. In Studies 1-3, we test this possibility across five identity-relevant domains.

A second potential influence on consumer identity occurs when retailers target consumers at a distributional extreme. For example, Casual Male Big and Tall sells clothing for larger men. Similarly, many online stores specialize in products geared toward those who hold strong Liberal views while others focus on those with extreme Conservative views. When retailers target consumers at the extremes they may also influence perceptions of the distribution of others and therefore where respondents fall in that distribution.

Since consumers often consider the individuals who are a brand's typical users (Aaker, 1991; McCracken, 1989), if a 
store sells clothing for tall men, consumers are more likely to bring to mind tall individuals who might be the store's primary customers. Indeed, Oyserman has described this interaction between social identities and product arrays: "When nothing looks right for the shopper trying on clothes in the store, a salient 'out of shape' identity makes for a different understanding than a salient 'academic' identity" (2009; p. 251). We take this logic a step further. We predict that bringing to mind stores that target consumers in the extremes (very tall people or very liberal people) will also shift the estimated distribution of others' heights or political leanings, and although it is unlikely to change a consumer's absolute beliefs or estimate of his own absolute height, it can nevertheless alter the consumer's relative estimate.

In Studies 4 and 5, we show that a retail product mix that highlights products designed for a tail of a consumer distribution may not move absolute estimates of self, but nevertheless will pull estimates of other consumers toward the tail, and therefore influence social identity by shifting estimates of relative standing away from that tail.

\section{Studies 1-3}

The first three studies explore whether varying consumer categorization schemas changes imagined distributions of others, relative standing, and perceptions of social identity. Past work has shown how response scales may affect people's estimates of their own absolute behavior ("How much TV do I watch?"; Schwarz et al., 1985), especially when the domain is a frequent, yet inconsequential behavior (Menon et al., 1995). Unlike prior work, we employed this scale only for estimates about others ("How much TV do others watch?"), essentially holding estimates of absolute behavior or characteristics fixed. We then observe distributional shifts and corresponding shifts in consumers' perceptions of relative standing in four identity domains.

All domains involved perceptions of identity-relevant traits and characteristics. Study 1 had two domains (Intelligence and Athletic Ability). Study 2 examined Conservatism/Liberalism. Study 3 examined environmentalism. In every study, participants provided three primary measures: 1) Absolute standing for the relevant trait or characteristic (either by estimating or by taking a quiz to measure it, depending on study), 2) An estimate of how 100 other participants were distributed into categories of standing, 3) An estimate of their own relative standing. ${ }^{1}$

Depending on categorization-schema condition, there were either more categories at the low or the high end of the scale (following Schwarz, 1999). Specifically, within domain, all participants estimated the distribution of 100 others across the same range and into the same number of categories. However the categorization schema differed in the breadth of categories

\footnotetext{
${ }^{1}$ Study 1 presented participants with three, counterbalanced domains. One domain (cell phone usage) was not included in the analyses because it is not clearly applicable to identity. Because that data was analyzed within domain rather than as part of a within-subject design, this repeated feature is not discussed.
}

at the low versus high end of the scale. This was achieved by using narrower increments at the scale's extremes. In the Low condition, the schema offered separate categories for each low score (e.g., 1, 2, 3, 4, 5) but fewer, wider categories for high scores (16 to 20). In the High condition, the schema offered separate categories for high scores $(16,17,18,19,20)$ but fewer, wider categories for low scores (1 to 5).

Note that individuals who assume both that categories have been incremented in a meaningful way and that there should be a wide dispersion across categories will automatically allocate a similar number of others to each category in the schema regardless of its breadth. As a result, this will produce greater mass over the narrow range categories in a distribution, whether they lay at the low or high end of the response scale. Critically, this will impact participants' inferences about their relative standing without impacting their absolute standing because they rely on these inferred distributions in their estimates of relative standing.

\section{Method}

All studies were computer-based, Study 1 using laboratory participants and 2 and 3 using Mechanical Turk participants. Participants answered questions within the domains of Intelligence and Athletic Ability (Study 1), Conservatism/ Liberalism (Study 2), or Environmentalism (Study 3; see Table 1 for more details).

First, participants' absolute standing was collected. This was measured in Study 1 via estimates about specific tasks related to the identity domain (e.g. number of correct trivia answers out of 20; see Table 1). In Study 2, absolute standing was calculated for participants using items from the Pew Center Political Typology Quiz. In Study 3, absolute standing was similarly calculated and provided after participants responded to a quiz composed of 12 environmental beliefs, attitudes, and behaviors.

Next, in all three studies, participants were asked to estimate the distribution of 100 randomly selected participants on the target trait or characteristic onto scales of varied increments, manipulated to have more (narrow) categories at either the high or the low end (see Table 1 for increments in each condition of each domain in each study). Finally, in all studies participants provided their relative standing by estimating the number of other participants who were below them on the target trait or characteristic.

\section{Results}

\section{Estimates of relative standing}

First, across all domains there was no difference in participants' absolute standing estimates (Study 1) nor actual absolute standing (Studies 2 and 3 ) by High versus Low category schema condition ( $t \mathrm{~s}<1.5, \mathrm{NS}$ ). Thus, any effects on relative standing would be due entirely to changes in how others were perceived. Indeed, estimates of relative standing did differ depending on condition. In all four domains, participants' estimates of the number of people who would fall below them 
Table 1

Methodological details for Studies 1-3.

\begin{tabular}{|c|c|c|c|c|}
\hline \multirow[t]{2}{*}{ Domain specific task } & \multirow[t]{2}{*}{ Study } & \multirow[t]{2}{*}{$\mathrm{N}$} & \multicolumn{2}{|c|}{ Distribution categories } \\
\hline & & & $\begin{array}{l}\text { High } \\
\text { condition }\end{array}$ & $\begin{array}{l}\text { Low } \\
\text { condition }\end{array}$ \\
\hline $\begin{array}{l}\text { Intelligence } \\
\qquad 20 \text { questions of Trivial Pursuit. }\end{array}$ & 1 & 303 & $\begin{array}{l}\text { Zero } \\
1 \text { to } 5 \\
6 \text { to } 10 \\
11 \text { to } 15 \\
16 \\
17 \\
18 \\
19 \\
20\end{array}$ & $\begin{array}{l}\text { Zero } \\
1 \\
2 \\
3 \\
4 \\
5 \\
6 \text { to } 10 \\
11 \text { to } 15 \\
16 \text { to } 20\end{array}$ \\
\hline $\begin{array}{l}\text { Athletic ability } \\
\text { Putting a golf ball into a cup. }\end{array}$ & 1 & 303 & $\begin{array}{l}12 \text { or less } \\
13 \text { to } 48 \\
49 \text { to } 60 \\
61 \text { to } 72 \\
73 \text { to } 84 \\
85 \text { to } 96 \\
97 \text { to } 108 \\
109 \text { to } 120 \\
121 \text { or more }\end{array}$ & $\begin{array}{l}12 \text { or less } \\
13 \text { to } 24 \\
25 \text { to } 36 \\
37 \text { to } 48 \\
49 \text { to } 60 \\
61 \text { to } 72 \\
73 \text { to } 84 \\
85 \text { to } 120 \\
121 \text { or more }\end{array}$ \\
\hline $\begin{array}{l}\text { Conservatism } \\
\text { Test of conservatism. }\end{array}$ & 2 & 121 & $\begin{array}{l}10-35 \\
36-40 \\
41-45 \\
46-50 \\
51-55 \\
56-60 \\
61-65 \\
66-70\end{array}$ & $\begin{array}{l}10-15 \\
16-20 \\
21-25 \\
26-30 \\
31-35 \\
36-40 \\
41-45 \\
46-70\end{array}$ \\
\hline $\begin{array}{l}\text { Environmentalism } \\
\text { Test of environmental concern. }\end{array}$ & 3 & 120 & $\begin{array}{l}0-19 \\
20-39 \\
40-44 \\
45-49 \\
50-54 \\
55-60\end{array}$ & $\begin{array}{l}0-4 \\
5-9 \\
10-14 \\
15-19 \\
20-39 \\
40-60\end{array}$ \\
\hline
\end{tabular}

were lower in High conditions (where there were more categories for others at the low end of the distribution) than Low conditions (see Table 2 for results).

\section{Distributions of others}

Support for the proposed mechanism was found in participants' estimated distribution of others. Fig. 1 visually captures the shifts in the density of the distributions in response to the manipulation. In order to statistically test these shifts, we used standard cutoffs (Gershoff \& Burson, 2011; Nisbett \& Kunda, 1985) to create three measures of distribution density in each domain - one for each tail of the distribution and one for the middle. ${ }^{2}$ We then conducted repeated measures ANOVAs in each domain with distribution density (middle, lower, and upper tail) as a within-subject variable and High versus Low category schema condition as a between-subject variable.

\footnotetext{
${ }^{2}$ These measures were created by summing the categories together. One distribution category was excluded from the middle categories, as recommended by Steenkamp, Allenby, Gupta, and Verducci (2001). In two domains (Intelligence and Environmentalism), discarding a middle category meant eliminating the measure of the middle altogether, which reduced the withinsubject measure to only 2 levels (upper tail and lower tail).
}

All four domains showed the expected interaction on distribution density suggesting that the category schema manipulation influenced imagined distributions (Intelligence, $F(1,301)=109.29, p<.001, \eta_{\mathrm{p}}^{2}=.266 ;$ Athletic Ability, $F(2,602)=54.87, p<.001, \eta_{\mathrm{p}}^{2}=.154$; Conservatism, $F(2$, $238)=183.53, p<.001, \eta_{\mathrm{p}}^{2}=.607$; Environmentalism, $F(1$, $\left.118)=167.11, p<.001, \eta_{\mathrm{p}}^{2}=.586\right)$. Contrasts confirmed that the tails of the estimated distributions differed by condition (see Table 3).

Further support for the proposed mechanism was obtained by exploring whether participants' estimates of the distributions of others statistically explained their relative estimates. First we looked at participants' estimated distributions and calculated what we called a "derived relative standing," which was the number of people from each participant's estimated distribution who fell below that participant's absolute standing. Next we used a two-step regression process (see Gershoff \& Burson, 2011). In the first step, estimates of relative standing were regressed on individuals' absolute scores. The second step included the derived measure in the model (see Table 4). Not surprisingly, in the first step, absolute scores predicted estimates of relative standing. More importantly, supporting the role of estimated distributions, in all domains, R-square increased when derived relative standing was in the model. In fact, in all domains, participants' absolute standing was no longer a significant predictor when derived relative standing was included. This means that the shape of the estimated distributions impacted estimates of relative standing, so changes in distribution shape due to the category schema manipulation subsequently changed perceptions of relative standing.

\section{Identity congruence}

A large body of literature predicts identity-congruent behavior when a particular identity is made salient (see Bhattacharjee, Berger, \& Menon, 2014). If we have truly manipulated social identity and that identity is relevant to the task at hand, preferences should also differ by condition (Oyserman et al., 2012). Therefore, after the relative standing measures in Study 3 , we also asked for participants' purchase preferences and intentions on seven identity-relevant items (e.g. "I will try to use less energy today", see Appendix A) on 1-7 scales. The scales were combined into one composite variable of "Congruence" (Cronbach's $\alpha=.80$ ). Congruence was found to depend on condition. Those led to believe they were more environmentally conscious than others were also more likely to say they would behave accordingly than those led to believe they were less environmentally conscious than others $\left(M_{\mathrm{High}}=4.25, \mathrm{SD}=1.22\right.$ vs. $M_{\text {Low }}=4.66, \mathrm{SD}=1.11 ; t(118)=1.94, p=.055$; Cohen's $\left.d=-.352 ; \mathrm{CI}_{.95}=-.009, .833\right)$.

\section{Discussion}

Studies 1 through 3 showed that the categorization schema available for distributing others impacts social identity as measured by relative standing and downstream variables such as energy consumption. Consistent with prior work on how consumers interpret response scales (Schwarz, 1994), we show 
Table 2

Absolute standing and relative standing estimates by condition for Studies 1-3.

\begin{tabular}{|c|c|c|c|c|c|c|c|}
\hline \multirow[t]{2}{*}{ Domain } & \multirow[t]{2}{*}{$\mathrm{N}$} & \multicolumn{2}{|c|}{ Distribution categories } & \multirow[t]{2}{*}{$t$} & \multirow[t]{2}{*}{ CI low } & \multirow[t]{2}{*}{ CI high } & \multirow[t]{2}{*}{ Cohen's $d$} \\
\hline & & High condition & Low condition & & & & \\
\hline \multicolumn{8}{|l|}{ Intelligence (Study 1) } \\
\hline $\begin{array}{l}\text { Mean absolute standing: estimated number of correctly } \\
\text { answered Trivial Pursuit questions, out of } 20 \text { (SD) }\end{array}$ & 303 & $9.92(4.88)$ & $10.70(4.20)$ & 1.48 & -.26 & 1.82 & \\
\hline $\begin{array}{l}\text { Mean relative standing: estimated number of other participants } \\
\text { scoring worse than themselves (SD) }\end{array}$ & & $35.99(26.09)$ & $56.64(25.84)$ & $6.89 * * *$ & 14.75 & 1.81 & .794 \\
\hline \multicolumn{8}{|l|}{ Athletic ability (Study 1 ) } \\
\hline $\begin{array}{l}\text { Mean absolute standing: estimated maximum distance (converted } \\
\text { to inches) to putt a ball into a cup }\end{array}$ & 303 & $69.60(66.77)$ & $61.88(71.95)$ & .93 & 2.55 & 18.67 & \\
\hline $\begin{array}{l}\text { Mean relative standing: estimated number of other participants } \\
\text { putting shorter distances than themselves (SD) }\end{array}$ & & $29.15(32.48)$ & $39.75(37.84)$ & $2.59 * *$ & -23.98 & 8.56 & .299 \\
\hline \multicolumn{8}{|l|}{ Conservatism (Study 2) } \\
\hline Mean absolute standing: actual conservatism score (SD) & 121 & $32.98(13.28)$ & $35.83(10.18)$ & 1.31 & -1.44 & 7.13 & \\
\hline $\begin{array}{l}\text { Mean relative standing: estimated number of other participants } \\
\text { less conservative than themselves (SD) }\end{array}$ & & $31.40(20.71)$ & $39.66(18.88)$ & $2.29 *$ & 1.11 & 15.41 & .420 \\
\hline \multicolumn{8}{|l|}{ Environmentalism (Study 3) } \\
\hline Mean absolute standing: actual environmentalism score (SD) & 120 & $23.88(5.94)$ & $24.03(4.65)$ & .15 & -1.78 & 2.08 & \\
\hline $\begin{array}{l}\text { Mean relative standing: estimated number of other participants } \\
\text { less environmental than themselves (SD) }\end{array}$ & & $33.72(18.41)$ & $45.63(19.55)$ & $3.44 * * *$ & 5.05 & 18.78 & .633 \\
\hline
\end{tabular}

Note. CIs are confidence intervals around the difference between high and low condition estimates.

$* p<.05$.

$* * p<.01$.

$* * * p<.001$

that when consumers are presented with many narrow category groupings, they estimate that more others fall into the same range compared to when they are presented with a single wider grouping. Identity-congruent behavior follows when relative standing seems relevant to the task at hand.

In addition to task-specific influences like response scales, a retailer offering a product mix targeted to just one end of a distribution of consumers may also impact estimates about others and thus relative standing and social identity. Unlike past work that has explicitly (and perhaps heavy-handedly) provided examples of extreme others, the next two studies allow the participants to infer those examples naturally. Furthermore, we remove the explicit task of providing distributions of others to ensure our effects do not depend on this step.

\section{Studies 4 and 5}

Studies 4 and 5 explore the role of the cognitive availability of stores and products in influencing consumers' estimates of their relative standing. In both studies, participants were exposed to websites that sold products specifically for consumers in distributional tails and estimated their own relative liberalism or height.

\section{Method}

All participants were recruited from online panels. Like the previous studies, they first indicated absolute standing: In Study 4, 247 participants self-reported how liberal they were on a 10-point scale. In Study 5, 420 participants provided their height in feet and inches. Next, participants examined images of websites for online retailers. Depending on condition, the websites made salient products for consumers at one extreme of the distribution or the other. In Study 4, participants evaluated five actual websites that sell products for liberals or for conservatives. ${ }^{3}$ In Study 5, participants saw one (fictitious) store — named either "Shopping Taller" or "Shopping Shorter" - that offered resources for buying products for taller or shorter consumers. ${ }^{4}$ Finally, participants estimated relative standing by providing the number of 100 participants who were less liberal (Study 4) or shorter than them (Study 5).

\footnotetext{
${ }^{3}$ In the liberal condition, the stores were The Liberal Store, Zazzle Liberal Tshirts, Hippie Shop, Liberated Liberal Political Gear, and Democratic Stuff. For the conservative condition, the stores were Patriot Depot, Right Wing Stuff, Major Surplus and Survival, Zazzle American Elephant, and Conservative Buys. A manipulation check confirmed that participants believed that the liberal websites were intended for more liberal consumers than conservative consumers $(M \mathrm{~s}=5.14$ vs. 2.40 on 7 -point scales, $t(122)=20.33, p<.001)$. Similarly, participants believed that the conservative websites were intended for more conservative consumers than liberal consumers $(M \mathrm{~s}=5.82$ vs. 2.53 , $t(123)=20.20, p<.001)$.

${ }^{4}$ After viewing the website, participants in this study also estimated the distribution of heights of 100 other people participating in the study by indicating the number that would fall into each of seven categories, $5^{\prime} 2^{\prime \prime}$ or shorter; $5^{\prime} 3^{\prime \prime}$ to $5^{\prime} 5^{\prime \prime}, 5^{\prime} 6^{\prime \prime}$ to $5^{\prime} 8^{\prime \prime}, 5^{\prime} 9^{\prime \prime}$ to $5^{\prime} 11^{\prime \prime}, 6^{\prime} 0^{\prime \prime}$ to $6^{\prime} 2^{\prime \prime}, 6^{\prime} 3^{\prime \prime}$ to $6^{\prime} 5^{\prime \prime}$, and $6^{\prime} 6^{\prime \prime}$ or taller. Using the analyses employed in Studies 1-3, we once again found the expected interaction on category density $(F(2,828)=21.43, p<.001)$ Contrasts revealed that participants shifted others from the bottom distribution category to the middle distribution category in the Tall condition $\left(F_{\mathrm{S}}>15.5\right.$, $p \mathrm{~s}<.001)$. Furthermore, when the derived relative standing measure was included in a two-step regression, it predicted participants' estimates of relative height $(B=.236, t(416)=2.99, p<.005)$, while actual own height was no longer significant $(B=-.005, t(416)=-.07, \mathrm{NS})$. As in Studies $1-3$, the shape of the estimated distribution predicted estimates of relative standing, thus changes in estimates of that distribution changed perceived relative standing.
} 


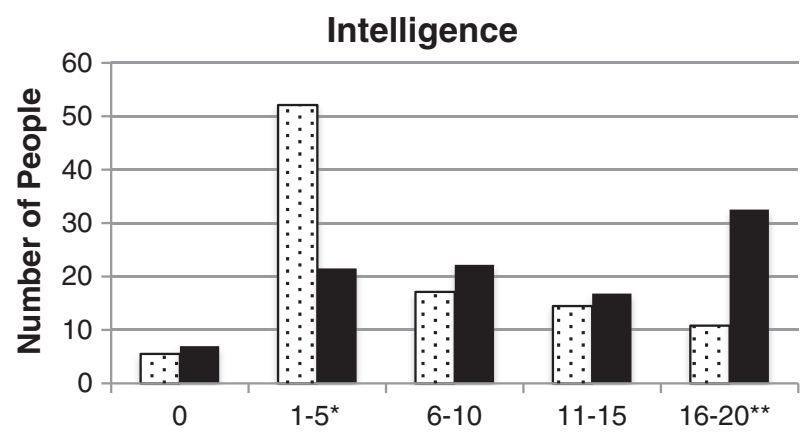

Estimated Number of Correct Trivia Answers

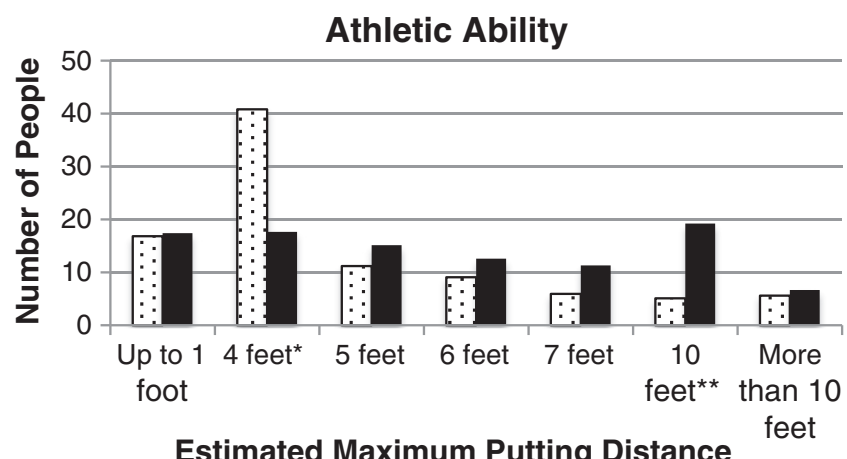

Estimated Maximum Putting Distance

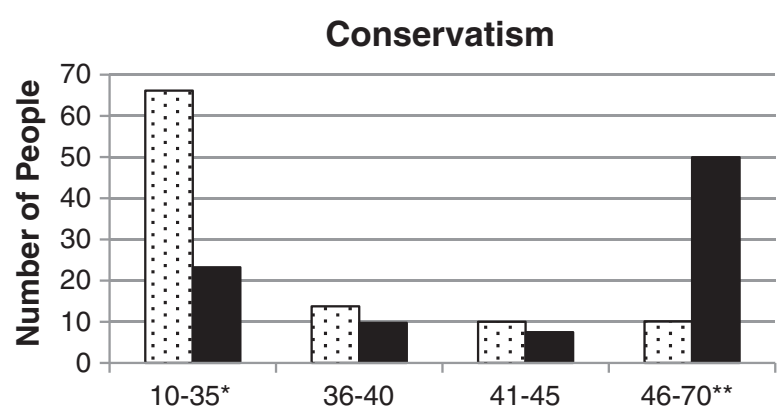

Estimated Score on Conservatism Quiz

\section{Environmentalism}

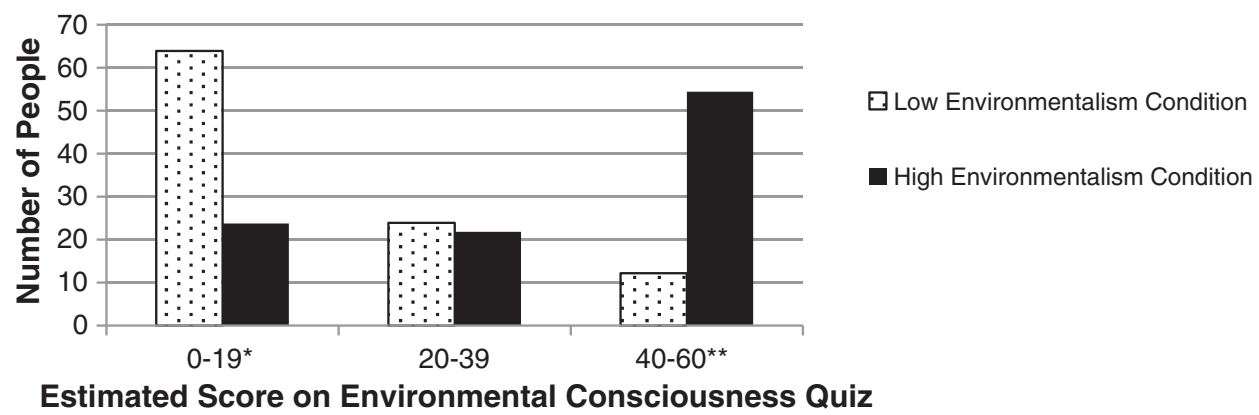

Note: * indicates increment that was expanded to smaller units in the low condition.

** indicates increment expanded to smaller units in the high condition.

Fig. 1. Estimates of others' by response category schema condition for Studies 1-3.

Results

In Study 4, despite random assignment, by chance there was a significant difference in absolute standing in liberalism by condition $(p=.037)$. This measure was collected first in the study, prior to any manipulation, so it is impossible that we influenced it. Therefore, we controlled for it by including it in an ANCOVA on relative standing. As predicted, in the Conservative 
Table 3

Contrasts showing change in density for Studies $1-3$.

\begin{tabular}{|c|c|c|c|c|c|c|c|}
\hline Domain & $\mathrm{N}$ & & Change in density low-high condition (SE) & $F$ & CI low & CI high & $\eta_{\mathrm{p}}^{2}$ \\
\hline \multirow[t]{2}{*}{ Intelligence (Study 1) } & 303 & Change in lower tail & $29.14(2.75)$ & $112.08 * *$ & 23.73 & 34.56 & .271 \\
\hline & & Change in upper tail & $-24.09(2.59)$ & $86.46 * *$ & -29.19 & -18.99 & .223 \\
\hline \multirow[t]{3}{*}{ Athletic ability (Study 1) } & 303 & Change in lower tail & $22.58(3.10)$ & $53.10 * *$ & 16.49 & 28.68 & .150 \\
\hline & & Change in middle & $-8.89(1.68)$ & $28.15 * *$ & -12.19 & -5.60 & .086 \\
\hline & & Change in upper tail & $-15.19(2.00)$ & $57.77 * *$ & -19.12 & -11.26 & .161 \\
\hline \multirow[t]{3}{*}{ Conservatism (Study 2) } & 121 & Change in lower tail & $42.88(3.08)$ & $194.54 * *$ & 36.80 & 48.97 & .620 \\
\hline & & Change in middle & $-2.032(1.06)$ & 3.67 & 1.105 & 15.412 & .030 \\
\hline & & Change in upper tail & $-39.85(2.97)$ & $180.31 * *$ & -45.72 & -33.97 & .602 \\
\hline \multirow[t]{2}{*}{ Environmentalism (Study 3) } & 120 & Change in lower tail & $40.15(3.66)$ & $120.21 * *$ & 32.90 & 47.40 & .505 \\
\hline & & Change in upper tail & $-42.25(3.19)$ & $175.08 * *$ & -48.57 & -35.93 & .597 \\
\hline
\end{tabular}

$* * p<.001$.

website condition, participants estimated being marginally more liberal than more people $(M=46.24, \mathrm{SD}=1.82)$ than in the Liberal website condition $(M=41.21, \mathrm{SD}=1.82 ; F(1$, 244) $\left.=3.79, p=.053, \eta_{\mathrm{p}}^{2}=.015 ; \mathrm{CI}_{.95}=-10.12, .06\right)$.

In Study 5, there was no significant difference in actual height of participants by Short $(M=66.55$ inches, $\mathrm{SD}=4.17)$ and Tall conditions $(M=66.22$ inches, $\mathrm{SD}=3.76, t(418)=.84$, $p=.404)$. However, as expected, estimates of relative height were affected by the manipulation. In the Short condition, participants estimated being relatively taller than more people $(M=35.06, \mathrm{SD}=25.17)$ than in the Tall condition $(M=27.77$; $t(418)=3.00, p=.003$; Cohen's $d=.294 ; \mathrm{CI}_{.95}=2.52$, 12.06).

\section{Discussion}

As in Studies 1-3, we observe that a commonplace cue about others played a critical role in participants' perceptions of their own standing relative to others. These two studies show that manipulating the availability of retailers carrying products for the high or low end of the distribution influenced estimates of relative standing on two identity relevant domains - being a liberal/conservative person or being a tall/short person.

\section{General discussion}

Consumers' judgments about themselves are dynamically created in context (Oyserman et al., 2012). Their social identities inherently hinge on comparisons with others. Our studies show that they are influenced by commonplace features of consumption contexts that also impact behavior. Shifts observed in relative perceptions are explained by shifts in estimates about the distribution of others, and thus might be predicted and avoided.

The studies reported here show that people's estimates about others are sensitive to quite subtle cues because they influence estimates of how others are distributed. In Studies 1-3, we observed differences in estimated distributions of others by influencing the number of separate groups in which people could fall at either end of the distribution. Altering this distribution shifted participants' estimates of traits and characteristics relative to others. Similarly, in Studies 4 and 5, we show that highlighting retailers who offer products for those in the tails of a distribution can change estimates of individuals' traits and characteristics relative to others. Perceptions of others can in fact explain the entire shift. For instance, despite the fact that participants' own height cannot change, we saw a difference in relative estimates of the heights in Study 5. Note also that the shifts produce biased perceived identities because participants cannot be simultaneously taller than only one-quarter of people and taller than more than one-third of people. Future research can extend these results by exploring the extent to which consumers "own" these social identities by measuring the importance or centrality of the relative perceptions.

These insights are relevant for choice architecture decisions. First, marketers must realize that, though consumers may have

Table 4

Regression parameters predicting estimates of relative standing in Studies 1-3.

\begin{tabular}{|c|c|c|c|c|c|c|c|}
\hline Domain & & Estimate of self & 'Derived relative standing' & R-square & Cohen's $\mathrm{f}^{2}$ & CI low & CI high \\
\hline \multirow[t]{2}{*}{ Intelligence (Study 1) } & Step 1 & $1.788 * *(.335)$ & - & .087 & & & \\
\hline & Step 2 & $-.026(.332)$ & $.551 * *(.051)$ & .339 & .513 & .450 & .652 \\
\hline \multirow[t]{2}{*}{ Athletic Ability (Study 1) } & Step 1 & $.172 * *(.029)$ & - & .111 & & & \\
\hline & Step 2 & $-.009(.036)$ & $.509 * *(.511)$ & .249 & .332 & .371 & .647 \\
\hline \multirow[t]{2}{*}{ Conservatism (Study 2) } & Step 1 & $.875 *(.149)$ & - & .265 & & & \\
\hline & Step 2 & $.263(.238)$ & $.273 *(.085)$ & .338 & .511 & .105 & .442 \\
\hline \multirow[t]{2}{*}{ Environmentalism (Study 3) } & Step 1 & $.169(.343)$ & - & .002 & & & \\
\hline & Step 2 & $.160(.288)$ & $.374 * *(.052)$ & .305 & .439 & .271 & .478 \\
\hline
\end{tabular}

Note: Parameters are unstandardized betas. Standard errors are in parentheses. CIs are confidence intervals around the parameter estimates for derived relative standing.

* Denotes significance at $p<.05$.

** Denotes significance at $p<.001$, R-square change from step 1 to step 2 significant at $p<.002$ for all four domains. 
fuzzy conceptions of where others stand, they still utilize those conceptions. Categories provided by marketers may influence this. For example, the ski area Vail uses a nine level system to categorize skiing ability. However, on its website (www.vail. com) the same nine categories are grouped in four sections as level 1 , levels 2 to 4 , levels 5 and 6 , and levels 7 to 9 . The research presented here suggests that skiers derive different relative perceptions depending on which schema they see: The four-category schema may lead to relative overestimation because the more narrowly defined level 1 category may be interpreted as indicating that a sizeable proportion of the population falls into this category, and that tail becomes cognitively available. When safety is a marketer's primary goal, employing the results of the last two studies may offset the effects shown in the first three to help consumers select appropriate products. For instance, a home page featuring the high end of available products (targeting the most skilled skiers, for example), could help push down inflated perceptions of relative standing.

Finally, this work suggests that, because forming a social identity requires the critical step of considering others as well as simply assessing absolute standing, social identities may be more susceptible to subtle situational cues than personal identities. Future research exploring situational cues that shift both of these components at once might shed light on differences in the malleability of each component.

\section{Appendix A. Measures of identity-congruence in Study 3}

"There are many brands and types of soaps on the market. Each advertises itself as being good for one group of people or another.

Below are descriptions of pairs of soaps. Indicate which you would prefer and by how much, if you were to make a choice for soap right now." (7-point scales anchored by the following)

"A good choice for ENVIRONMENTALLY CONSCIOUS PEOPLE" and "A good choice for ACTIVE PEOPLE"

"A good choice for ENVIRONMENTALLY CONSCIOUS PEOPLE" and "A good choice for WORKING PEOPLE"

"A good choice for ENVIRONMENTALLY CONSCIOUS PEOPLE" and "A good choice for GERM CONCERNED PEOPLE"

"A good choice for ENVIRONMENTALY CONSCIOUS PEOPLE" and "A good choice for YOUNG PEOPLE"

"A good choice for ENVIRONMENTALLY CONSCIOUS PEOPLE" and "A good choice for MATURE PEOPLE"

"Rate your agreement with the following statements" (1-7 Likert scale)

I will try to use less water today.

I will try to use less energy today.

\section{Appendix B. Supplementary data}

Supplementary data to this article can be found online at http://dx.doi.org/10.1016/j.jcps.2015.01.008.

\section{References}

Aaker, D. A. (1991). Managing brand equity: Capitalizing on the value of a brand name. New York: Free Press.

Aaker, D. A. (1997). Should you take your brand to where the action is? Harvard Business Review, 75(5), 135-142.

Berger, J., \& Rand, L. (2008, August). Shifting signals to help health: Using identity signaling to reduce risky health behaviors. Journal of Consumer Research, 35, 509-518.

Bhattacharjee, A., Berger, J., \& Menon, G. (2014). When identity marketing backfires: Consumer agency in identity expression. Journal of Consumer Research, 41, 294-309.

Biernat, M. (2003). Toward a broader view of social stereotyping. American Psychologist, 58(12), 1019-1027.

Burson, K. A. (2007, June). Consumer-product skill matching: The effects of difficulty on relative self-assessment and choice. Journal of Consumer Research, 34, 104-110.

Chernev, A., Hamilton, R., \& Gal, D. (2011, May). Competing for consumer identity: Limits to self-expression and the perils of lifestyle branding. Journal of Marketing, 75, 66-82.

Festinger, L. (1954). A theory of social comparison processes. Human Relations, 7, 117-140.

Gershoff, A., \& Burson, K. A. (2011). It's not just me: The role of inferred distributions of others in estimates of relative standing. Journal of Consumer Research, 38(3), 407-419.

Grice, H. P. (1975). Logic and conversation. In P. Cole, \& J. L. Morgan (Eds.), Syntax and semantics 3: Speech arts (pp. 41-58). New York: Academic Press.

Haberstroh, S., Oyserman, D., Schwarz, N., Kühnen, U., \& Ji, L. -J. (2002). Is the interdependent self more sensitive to question context than the independent self? Self-construal and the observation of conversational norms. Journal of Experimental Social Psychology, 38, 323-329.

Johnson, S. E., Richeson, J. A., \& Finkel, E. (2011). Middle-class and marginal? Socioeconomic status, stigma, and self-regulation at an elite university. Journal of Personality and Social Psychology, 100(5), 838-852.

Kruglanski, A. W., \& Mayseless, O. (1990). Classic and current social comparison research: Expanding the perspective. Psychological Bulletin, 108(2), 195-208.

McCracken, G. (1989). Who is the celebrity endorser? Cultural foundations of the endorsement process. Journal of Consumer Research, 16, 310-321.

Menon, G., Block, L. G., \& Ramanathan, S. (2002, March). We're at as much risk as we are led to believe: Effects of message cues on judgments of health risk. Journal of Consumer Research, 28, 533-549.

Menon, G., Raghubir, P., \& Schwarz, N. (1995, September). Behavioral frequency judgments: An accessibility-diagnosticity framework. Journal of Consumer Research, 22, 212-228.

Miller, D. T., Turnbull, W., \& McFarland, C. (1988). Particularistic and universalistic evaluation in the social comparison process. Journal of Personality and Social Psychology, 55, 908-917.

Moore, D. A. (2007). Not so above average after all: When people believe they are worse than average and its implications for theories of bias in social comparison. Organizational Behavior and Human Decision Processes, 102(1), 42-58.

Moorman, C., Diehl, K., Brinberg, D., \& Kidwell, B. (2004). Subjective knowledge, search locations, and consumer choice. Journal of Consumer Research, 31(3), 673-680.

Nisbett, R. E., \& Kunda, Z. (1985). Perception of social distributions. Journal of Personality and Social Psychology, 48(2), 297-311.

Oyserman, D. (2001). Self-concept and identity. In A. Tesser, N. Schwarz, A. Tesser, \& N. Schwarz (Eds.), The Blackwell handbook of social psychology (pp. 499-517). Malden, MA: Blackwell.

Oyserman, D. (2009). Journal of Consumer Psychology, 19, 250-260.

Oyserman, D., Elmore, K., \& Smith, G. (2012). Self, self-concept, and identity. In M. R. Leary, \& J. P. Tagney (Eds.), Handbook of self and identity (pp. 69-104). New York: The Guilford Press.

Prelec, D., Wernerfelt, B., \& Zettelmeyer, F. (1997). The role of inference in context effects: Inferring what you want from what is available. Journal of Consumer Research, 24(1), 118-125.

Raeff, C. (1997). Individuals in relationships: Cultural values, children's social interactions, and the development of an American individualistic self. Developmental Review, 17, 204-238. 
Schwarz, N. (1994). Judgment in a social context: Biases, shortcomings, and the logic of conversation. Advances in Experimental Social Psychology, 26, $123-162$.

Schwarz, N. (1996). Cognition and communication: Judgmental biases, research methods and the logic and conversation. Hillsdale, NJ: Erlbaum.

Schwarz, N. (1999). Self-reports: How the questions shape the answers. American Psychologist, 54(2), 93-105.

Schwarz, N., Hippler, H. J., Deutsch, B., \& Strack, F. (1985). Response scales: Effects of category range on reported behavior and comparative judgments. Public Opinion Quarterly, 49, 388-395.

Schwarz, N., \& Scheuring, B. (1988). Judgments of relationship satisfaction: Inter- and intraindividual comparisons as a function of questionnaire structure. European Journal of Social Psychology, 18, 485-496.
Steenkamp, J. -B., Allenby, G., Gupta, S., \& Verducci, J. (2001). Analysis of constant sum scores. Journal of Consumer Psychology, 10(1/2), 41-43.

Verplanken, B., \& Sato, A. (2011). The psychology of impulse buying: An integrative self-regulation approach. Journal of Consumer Policy, 34(2), 197-210.

Winterich, K. P., Mittal, V., \& Ross, W. T. (2009). Donation behavior toward in-groups and out-groups: The role of gender and moral identity. Journal of Consumer Research, 36(2), 199-214.

Zhang, Y., \& Khare, A. (2009, October). The impact of accessible identities on the evaluation of global versus local products. Journal of Consumer Research, 36, 524-537. 